\title{
Electrochemical and Photocatalytic Reactions of Polycyclic Aromatic Hydrocarbons Investigated by Raman Spectroscopy
}

\author{
Denise S. Cordeiro and Paola Corio* \\ Instituto de Química, Universidade de São Paulo, CP 26077, 05513-970 São Paulo-SP, Brazil
}

Este trabalho apresenta o estudo do comportamento fotoquímico de hidrocarbonetos policíclicos aromáticos (HPAs), potenciais poluentes secundários em reações em aerossóis, através de espectroscopia Raman em comparação com seu comportamento eletroquímico. Os HPAs estudados incluem pireno, antraceno, fenantreno e fluoreno. Esses foram adsorvidos sobre o catalisador $\mathrm{TiO}_{2}$ e irradiados com radiação ultravioleta $(254 \mathrm{~nm})$. A oxidação eletroquímica foi estudada via espectroscopia Raman intensificada pela superfície (SERS) in situ e levou à formação de produtos carbonilados. Intermediários oxidados contendo o grupo $\mathrm{C}=\mathrm{O}$ foram também observados nos processos de fotodegradação. A comparação entre os intermediários formados nos processos fotoquímicos e eletroquímicos revela produtos idênticos para o antraceno, mas não para o pireno. Esse resultado advém da diferença de mecanismo para esses dois processos. A degradação fotocatalítica sobre $\mathrm{TiO}_{2}$ é iniciada por radicais hidroxila, enquanto a oxidação eletroquímica é iniciada por transferência eletrônica direta com o HPA adsorvido no eletrodo, gerando cátions radicais do HPA que desencadeiam as reações subseqüentes.

This paper presents the study of photochemical behavior of polycyclic aromatic hydrocarbons (PAHs), potential pollutants in secondary reactions in aerosols, through Raman spectroscopy compared with its electrochemical behavior. The PAHs studied include pyrene, anthracene, phenanthrene and fluorene. These were adsorbed onto $\mathrm{TiO}_{2}$ and irradiated with ultraviolet light (254 nm). Their electrochemical oxidation was studied by in situ Surface-enhanced Raman Scattering (SERS) and led to the formation of carbonyl-containing products. Oxidized intermediates bearing the $\mathrm{C}=\mathrm{O}$ group were also formed during photodegradation. The joint analysis of the photodegradation data with those produced by electrochemical means - using spectroscopic techniques for the identification and characterization of the products - revealed the formation of identical products for anthracene, but not for pyrene. A reasonable explanation for this difference in results is that photochemical and electrochemical oxidation reactions proceed via different mechanisms. While photocatalytic degradation over $\mathrm{TiO}_{2}$ is initiated by hydroxyl radicals, electrochemical oxidation is initiated by the direct electron transfer from adsorbed PAH to the electrode, generating PAH cation radicals that undergo subsequent reactions.

Keywords: advanced oxidative processes, photocatalysis, $\mathrm{TiO}_{2}$, spectroelectrochemistry, SERS

\section{Introduction}

Excessive concentrations of particulate matter in the atmosphere are cause for significant concern in many metropolitan areas around the world. This particulate matter exhibits dynamic behavior owing to potential chemical and photochemical reactions, changing its composition according to time and environment. Polycyclic aromatic hydrocarbons (PAHs), a class of chemicals present in particulate matter, are of special interest due to their

\footnotetext{
*e-mail: paola@iq.usp.br.
}

mutagenic and carcinogenic properties. ${ }^{1,2}$ PAHs are characterized by the presence of two or more aromatic rings in their structure. These compounds are among the most persistent organic pollutants and are generally produced by the burning of organic fuels in an oxygen-depleted environment. Among the sources of PAHs are diesel and gas engine exhaust, waste plant incineration exhaust, wood and coal combustion, cigarette smoke, as well as various industrial processes. PAHs are present in the atmosphere as volatile and semi-volatile pollutants, as well as in the form of particulate matter. The U.S. Environment Protection Agency (EPA) focuses on the study of sixteen PAHs, among 
which are naphthalene, anthracene, phenanthrene, pyrene, fluorene, chrysene, fluoranthene, benzo(a)anthracene, benzo(a)pyrene, and dibenzo(a,h)anthracene. Benzo(a) pyrene is one of the most extensively studied of these, in part because of its high concentration in the human environment. ${ }^{3}$ Nitro- and oxygen derivatized PAHs are also very important from an environmental perspective. ${ }^{4}$

Analysis of the photochemical and electrochemical behavior of PAHs is relevant for clarifying some aspects of complex environmental systems. In this work, we exposed PAHs to UV radiation to characterize their photolysis products. Two levels of information were obtained, including: (i) PAH photochemical reactivity, which will increase understanding of their behavior in the atmosphere; and (ii) PAH photodegradation potential, which may be useful for designing future pollution control strategies. Investigations included the use of titanium dioxide $\left(\mathrm{TiO}_{2}\right)$ as a photocatalyst, which enabled a comparison of degradation products in the absence and presence of a catalyst. This type of heterogeneous photocatalysis with semiconducting materials is an efficient and broadly used approach for decomposing organic pollutants in water and air.

A significant amount of research has been carried out by other research groups, addressing photodegradation processes for different molecules with $\mathrm{TiO}_{2}$ as a catalyst. Some molecules studied include phenol, chlorophenol, organo-chlorinated compounds, and other dyes, ${ }^{5,6}$ all of which are common pollutants found in industrial effluents. Molecular degradation and kinetics parameters were determined in these studies using UV-Visible (UV-Vis) electronic spectroscopy and mass spectrometry. In the research presented here, we apply vibrational spectroscopy to gain additional information concerning mechanisms involved in PAHs photodegradation processes. Raman, and specifically surface-enhanced Raman spectroscopy (SERS), enabled monitoring of chromophore degradation and also permitted the characterization of intermediates and the final reaction products. These techniques are complementary to those traditionally used in this field.

At present there are relatively few studies on the photodegradation of PAHs in the presence of $\mathrm{TiO}_{2}$, in part owing to the low aqueous solubility of these compounds. Moreover, there are contradictory reports in the literature concerning the photocatalytic action of $\mathrm{TiO}_{2}$ in degrading PAHs. ${ }^{7-10}$ For example, the photochemical degradation of fluorene and several of its derivatives in aqueous solution were investigated in the presence and absence of $\mathrm{TiO}_{2}$. Results from this study suggest that these PAHs are eliminated more rapidly in the absence of the semiconducting material. ${ }^{8}$ However, a conflicting report has shown that pyrene photodegradation proceeds more efficiently in the presence of $\mathrm{TiO}_{2} \cdot{ }^{10}$ Owing to the importance of this research and recent contradicting results, it is apparent that the challenging problem of $\mathrm{TiO}_{2}$ catalyzed $\mathrm{PAH}$ photodegradation deserves further investigation.

\section{Materials and Methods}

\section{Materials and instrumentation}

UV-Vis-near infrared (UV-Vis-NIR) spectra were obtained with a Shimadzu UVPC-3101 scanning spectrophotometer. Raman spectra were acquired on a Renishaw Raman System 3000 equipped with a CCD and coupled to an Olympus microscope (BTH2), enabling rapid accumulation of Raman spectra with a spatial resolution of approximately $1 \mu \mathrm{m}$ (micro-Raman). The laser beam was focused at 80 times magnification onto the sample ( $\times 80$ lens). Laser power was always kept below $0.7 \mathrm{~mW}$ at the sample. Experiments were performed under ambient conditions using a back-scattering geometry. Samples were irradiated with the $632.8 \mathrm{~nm}$ line of a helium-neon (He-Ne) laser (Spectra Physics). Fourier transform - Raman (FT-Raman) spectra of solid samples were recorded at room temperature in a RFS 100 FT-Raman Bruker spectrometer using the fundamental of a Nd:YAG laser (1064 nm).

Commercial Degussa $\mathrm{P} 25 \mathrm{TiO}_{2}$ (anatase/rutile $=3 / 1$, surface area $=50 \mathrm{~m}^{2} \mathrm{~g}^{-1}$, mean particle size $=30 \mathrm{~nm}$ ) was used in this work. Other chemicals and solvents were obtained from Aldrich and Merck. All chemicals were analytical grade and were used as received without further purification. Working solutions were prepared using these analytical grade chemicals and doubly distilled water. All organic solvents were of spectroscopic grade.

\section{Catalyst preparation}

The most significant challenge associated with studying PAH photodegradation results from the low aqueous solubility of PAHs. To address this problem, we took advantage of the high affinity between the PAHs and $\mathrm{TiO}_{2}$, first adsorbing $\mathrm{PAHs}$ onto $\mathrm{TiO}_{2}$ particles in an organic phase. ${ }^{9,10}$ Photochemical behavior of PAHs was then investigated over thin films.

Pre-adsorption of PAHs onto Degussa $\mathrm{P} 25 \mathrm{TiO}_{2}$ particles was done based on methodology proposed by Wen et al. ${ }^{10}$ Briefly, $\mathrm{TiO}_{2}$ was added to a solution of the PAH in diethyl ether with a mass proportion of $2 \mathrm{wt} \%\left(\mathrm{PAH}_{\mathrm{TiO}}\right)$. The suspension $\left(0.2 \mathrm{~g}\right.$ of PAH modified $\mathrm{TiO}_{2} / 10 \mathrm{~mL}$ of diethyl ether) was magnetically stirred until complete volatilization of the solvent was achieved. 


\section{Photocatalytic procedure}

Photodegradations were carried out by exposure of the $\mathrm{PAH} / \mathrm{TiO}_{2}$ composite to UV radiation. The light source was an $8 \mathrm{~W}$ mercury lamp (254 nm) held at a distance of $10 \mathrm{~cm}$ from the HPA-modified surface. Radiation intensity at the film surface was $c a .500 \mu \mathrm{W} \mathrm{cm} \mathrm{cm}^{-2}$, as measured with a Coherent Radiation (Palo Alto) power meter (model 212).

\section{Spectroelectrochemical measurements}

For SERS experiments, solid gold electrodes with $0.2 \mathrm{~cm}^{2}$ geometrical area were used. Electrodes were constructed in specially designed Teflon ${ }^{\circledR}$ sample holders in order to fit in the spectro-electrochemical cell. A standard $\mathrm{Ag} / \mathrm{AgCl} / \mathrm{KCl}$ (sat.) electrode was used for reference with a pure platinum wire as the counter electrode. In order to activate the electrodes, successive oxidation/reduction cycles $\left(50 \mathrm{mV} \mathrm{s}^{-1}\right)$ were performed in the working solution (aqueous $0.1 \mathrm{~mol} \mathrm{~L}^{-1} \mathrm{KCl}$ ). This electrode was then immersed on a saturated aqueous solution of the investigated PAH for $12 \mathrm{~h}$. This modified electrode was rinsed with water, transferred to the electrochemical cell. In situ SERS spectra were then recorded by varying the applied potential in steps of $0.1 \mathrm{~V}$. A PAR 263 potentiostat/galvanostat from EG\&G was used for this electrochemical setup.

\section{Results and Discussion}

\section{Anthracene}

\section{Photochemistry with $\mathrm{TiO}_{2}$ photocatalyst}

The photocatalytic reaction of anthracene adsorbed onto $\mathrm{TiO}_{2}$ was monitored by recording changes in the Raman spectra as a function of UV irradiation time (Figure 1). Intermediates were formed at the semiconductor/air interface. It is important to mention that photodegradation in the semiconducting/air interface, as reported here, could follow different mechanism than photodegradation in aqueous solutions. In this case, solution phase products and surface generated products could be distinct. Significant changes in the Raman spectra were detected after $235 \mathrm{~min}$ of irradiation. Upon exposure to UV light, atmospheric humidity and oxygen, the adsorbed anthracene was transformed into a species with characteristic vibrational modes at 1031, 1600 and $1665 \mathrm{~cm}^{-1}$. The $1665 \mathrm{~cm}^{-1}$ vibrational mode can be assigned to the presence of carbonyl $(\mathrm{C}=\mathrm{O})$ groups, indicating PAH oxidation. Relative intensity between this product absorption band and those characteristic of anthracene (1401 $\mathrm{cm}^{-1}$, for example) increased with UV exposure, indicating an increase in the concentration of oxidation photoproducts. Data shown in Figure 1 characterizes the initial steps of photodegradation, as the original PAH is apparent in the spectrum even after 613 min of UV exposure.

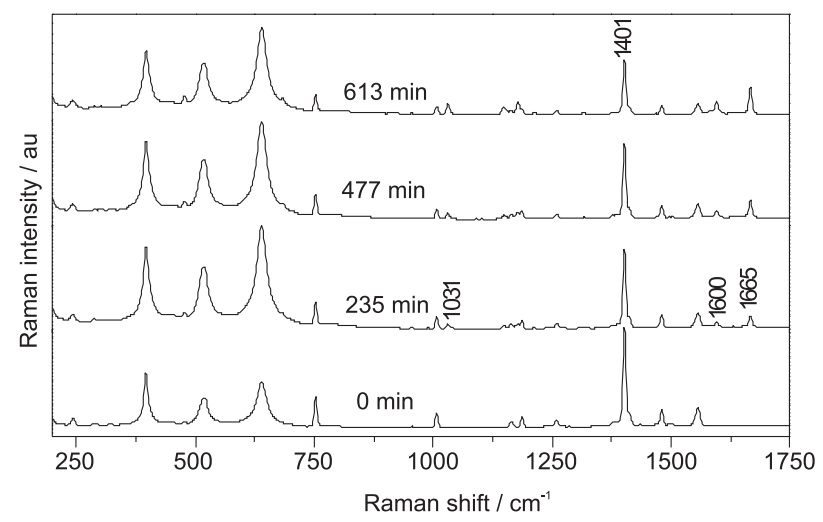

Figure 1. FT-Raman spectra for anthracene adsorbed on the $\mathrm{TiO}_{2}$ surface ( $2 \mathrm{wt} \%$ ) corresponding to progressively longer UV-irradiation times (bottom to top); $\lambda_{\text {exc. }}=1064 \mathrm{~nm}$.

Expected anthracene oxidation products are hydroxyanthracenes and anthraquinones. The most stable anthraquinones are those with two carbonyl groups in the same ring. ${ }^{11}$ Characteristic photoproduct vibrational modes (i.e., 1031, 1600 and $1665 \mathrm{~cm}^{-1}$ ) can be assigned to 9,10 -anthraquinone. ${ }^{12}$ This intermediate product has also been observed in the photocatalytic degradation of saturated anthracene aqueous solutions over thin films of porous $\mathrm{TiO}_{2} \cdot{ }^{7}$ Results presented in Figure 1 suggest that 9,10-anthraquinone does not photodegrade significantly, demonstrating that it accumulates as anthracene decomposes. Photocatalytic degradation of anthracene with $\mathrm{TiO}_{2}$ thus leads to the formation of an intermediate photoproduct (i.e., 9,10-anthraquinone) that resists further degradation. Figure 2 proposes a mechanism leading to the formation of 9,10-anthraquinone. It is important to point out that the semiquinone II presented as an intermediate, while not being observed during the photodegradation process, has been identified through spectroelectrochemistry as will be discussed.

\section{Spectroelectrochemistry}

To compare the photochemical and electrochemical oxidation reactions of PAHs, the electrochemical behavior of these molecules, while adsorbed onto gold electrodes, was studied using in situ SERS. SERS is a well established and important analytical technique for the characterization of surface adsorbates and chemical transformations that occur on metallic surfaces. ${ }^{13,14}$ Application of SERS for the study of in situ electrochemical processes can thus 


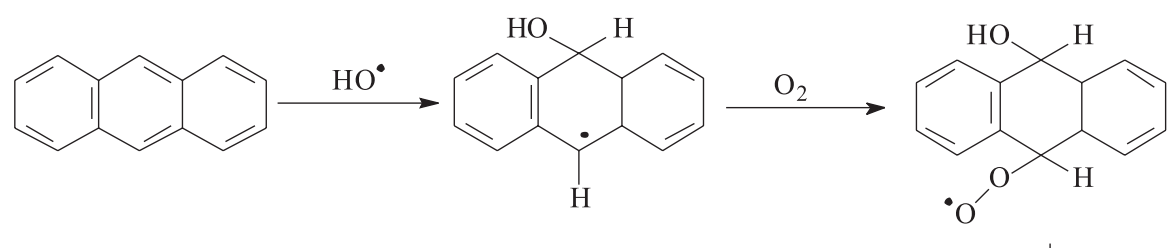<smiles>CC1C=CC2C(=O)c3ccccc3C(=O)C2C=C1</smiles>

Quinone (9,10-anthra)

II<smiles>O=C1c2ccccc2C(O)C2C=CC=CC12</smiles>

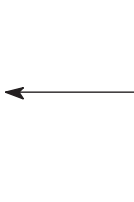<smiles>OC1c2ccccc2C(O)(O)C2C=CC=CC12</smiles>

Semiquinone I

Figure 2. Proposed mechanism consistent with a radical addition to 9 and $10 .^{7}$ It must be emphasized that the 'regular' chemistry of aromatic compounds is via substitution reactions. However, these central PAHs carbons have some special reactivity toward addition reactions on account of their non-aromaticity in comparison with the rest of the molecule.

provide relevant information about the chemical nature of species generated on the surfaces of electrodes. This technique can also yield information on the mechanisms of such reactions. ${ }^{15}$

SERS spectra of anthracene adsorbed on a gold electrode for several anodic applied potentials are shown in Figure 3. The SERS spectrum at $0.0 \mathrm{~V}$ is similar to the solid-state anthracene spectrum, indicating that anthracene adsorption on the SERS-active metallic surface does not significantly disturb the PAH molecular structure. Recently it has been demonstrated that PAH adsorption on nanostructured gold surfaces may cause their oxidative degradation. ${ }^{16,17}$ When the applied potential is made more positive than $+0.9 \mathrm{~V}$, Raman spectral changes indicate the electrochemical oxidation of adsorbed anthracene.

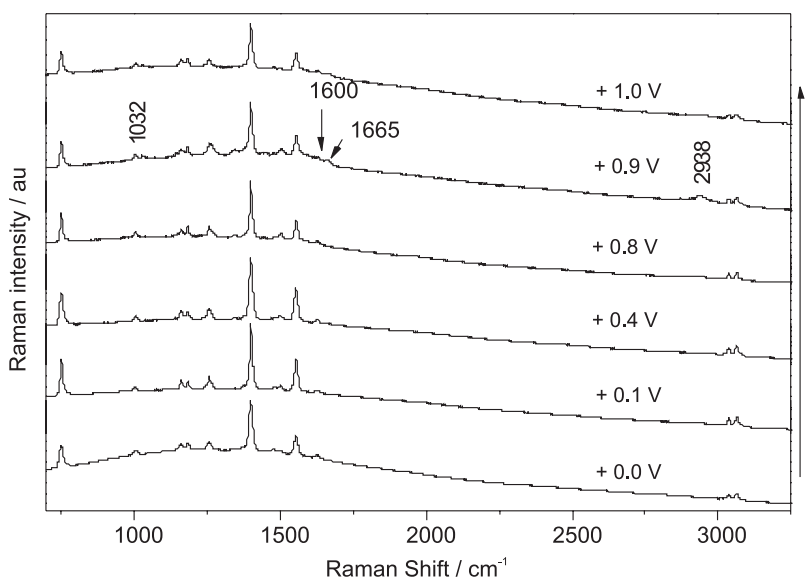

Figure 3. In situ Raman spectra of anthracene adsorbed on a gold surface in $\mathrm{KCl} 0.1 \mathrm{~mol} \cdot \mathrm{L}^{-1}$ aqueous solution obtained at anodic polarization. Potentials shown are versus $\mathrm{Ag} / \mathrm{AgCl} ; \lambda_{\text {exc. }}=632.8 \mathrm{~nm}$. The arrow on the right indicates the order in which traces were taken.
New Raman bands, characteristic of oxidized species, are observed at 1032, 1600 and $1665 \mathrm{~cm}^{-1}$. Changes are also seen in the high frequency region of the spectra, where characteristic vibrational modes of aromatic and aliphatic $\mathrm{CH}$ stretching appear. It is interesting to point out the appearance of a band at $2938 \mathrm{~cm}^{-1}$ at $+0.9 \mathrm{~V}$, that fades for more positive potentials, as seen at $+1.0 \mathrm{~V}$. This feature can be assigned to an aliphatic $\mathrm{CH}$ stretching mode, characteristic of semiquinone I, which is further oxidized to 9,10-anthraquinone. It can therefore be proposed the initial formation of a hydroquinone intermediated - that possess aliphatic hydrogen - that oxidizes to the molecule that gives rise to the characteristic spectra observed at $+1.0 \mathrm{~V}$. This is also in accordance to the oxidation mechanism proposed by Pal and Sharon (Figure 2). ${ }^{7}$

In Figure 4, a comparison is made between: (i) the FT-Raman spectrum of initial products from photodegradation of anthracene over $\mathrm{TiO}_{2}$ and (ii) the SERS spectrum of products from electrochemically oxidized anthracene in aqueous solution. It is striking to notice the resemblance of the photodegradation product at the semiconductor/air interface and the electrochemical oxidation product in aqueous solution (for an applied potential of $+0.9 \mathrm{~V}$ ). Both spectra show the same vibrational modes at 1031, 1600 and $1665 \mathrm{~cm}^{-1}$. We conclude that the initial light-induced photodegradation process of anthracene on $\mathrm{TiO}_{2}$ induces production of the same compound in comparison with direct electrochemical oxidation of the PAH adsorbed on a gold electrode.

Similar photo and electrochemical behaviors were observed for 9-nitroanthracene, that was photo (and eletro) oxidized to the respective 9,10-nitroanthraquinone. 


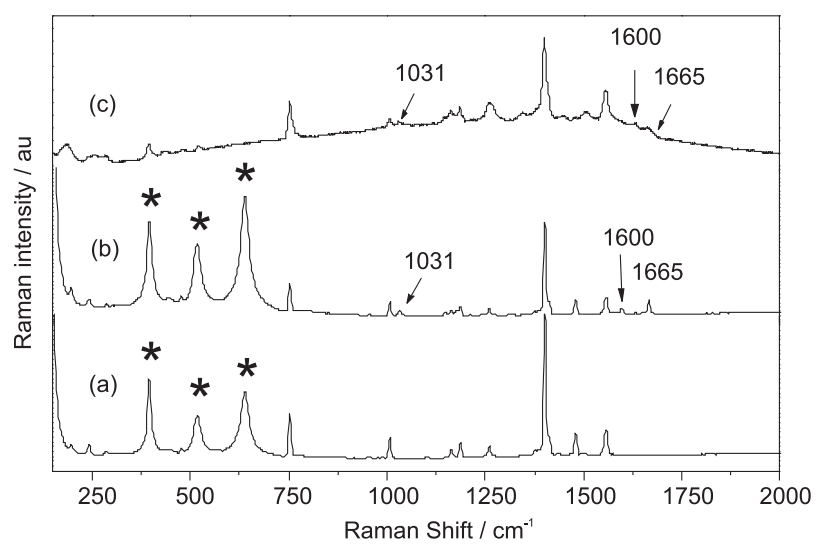

Figure 4. FT-Raman spectra of anthracene adsorbed on $\mathrm{TiO}_{2}$ (a) before and (b) after UV irradiation for $235 \mathrm{~min} ; \lambda_{\text {exc }}=1064 \mathrm{~nm}$. (c) SERS spectra of anthracene adsorbed on a gold surface at an applied potential of $+0.9 \mathrm{~V}$ (oxidized anthracene); $\lambda_{\text {exc. }}=632.8 \mathrm{~nm}$. Applied potentials shown are versus $\mathrm{Ag} / \mathrm{AgCl}$. The asterisk (*) indicates $\mathrm{TiO}_{2}$ vibrational modes.

Phenanthrene was also studied, and its photooxidation on $\mathrm{TiO}_{2}$ has resulted in considerable mineralization (without identification of the quinoidal intermediates), even though we had expected a similar reactivity to anthracene. The reaction time was, for anthracene and phenanthrene, of $10 \mathrm{~h}$, which indicates that the latter PAH is a more sensitive substrate to photodegradation as compared to anthracene. This can be verified in the spectra of Figure 5 .

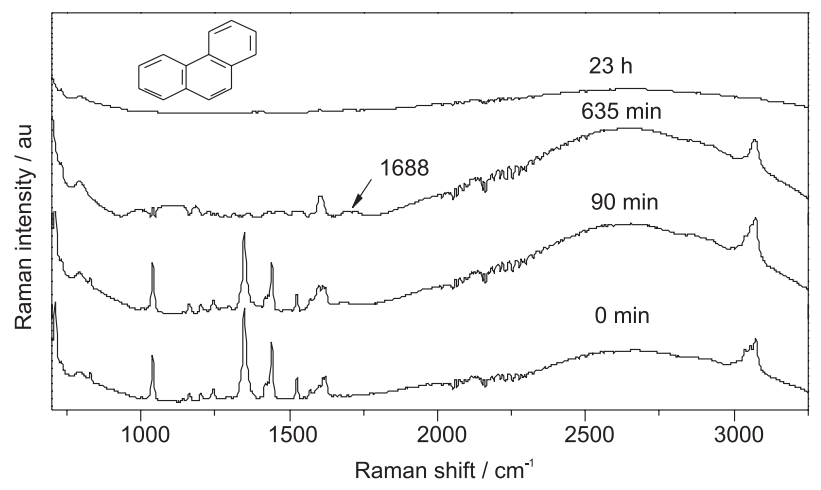

Figure 5. FT-Raman spectra for phenanthrene adsorbed on a $\mathrm{TiO}_{2}$ surface ( $2 \mathrm{wt} \%$ ) corresponding to progressively longer UV-irradiation times (bottom to top); $\lambda_{\text {exc. }}=1064 \mathrm{~nm}$ and mineralization of organic matter.

\section{Pyrene}

\section{Photochemistry with $\mathrm{TiO}_{2}$ photocatalyst}

The photocatalytic process for pyrene adsorbed onto $\mathrm{TiO}_{2}$ was monitored using FT-Raman spectroscopy, as shown in Figure 6. Structural PAH changes induced by UV light irradiation were observed. After $290 \mathrm{~min}$ of UV irradiation, the Raman spectrum suggests complete pyrene degradation, owing to the conspicuous absence of characteristic pyrene vibrational bands (e.g., 1630, 1241 and $1065 \mathrm{~cm}^{-1}$ ).

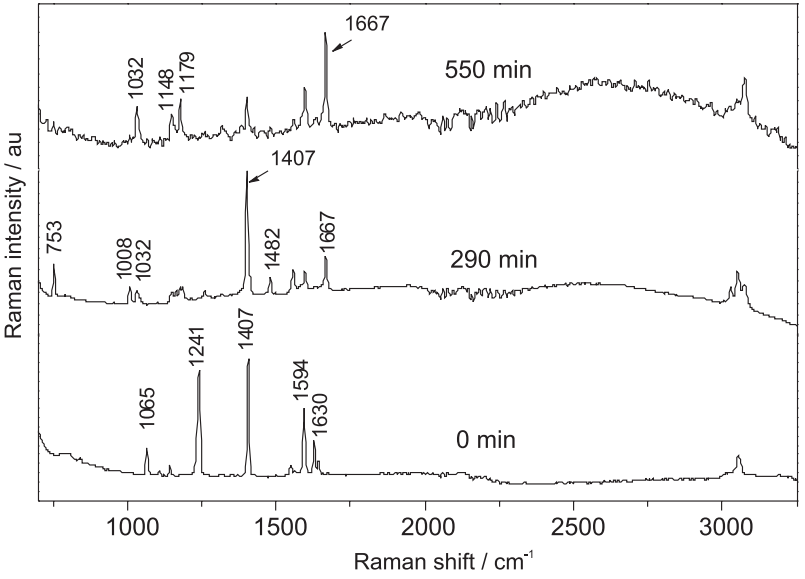

Figure 6. FT-Raman spectra for pyrene adsorbed onto a $\mathrm{TiO}_{2}$ surface ( $2 \mathrm{wt} \%$ ) corresponding to progressively longer UV-irradiation times (bottom to top); $\lambda_{\text {exc. }}=1064 \mathrm{~nm}$.

The intermediate photoproduct has a vibrational mode at $1667 \mathrm{~cm}^{-1}$ (assigned to $\mathrm{v}_{\mathrm{C}=\mathrm{O}}$ ), indicating formation of an oxidized species. Relative intensity of carbonyl spectral features increases as the photochemical reaction proceeds. Additional vibrational features of the intermediate product include bands at 1482, 1032, 1008 and $753 \mathrm{~cm}^{-1}$. Interestingly, this first intermediate further degrades, and after 550 min of UV irradiation, the carbonyl band dominates the spectrum. New vibrational modes, characteristic of the subsequent photochemical reaction products, also begin to appear at 1148 and $1179 \mathrm{~cm}^{-1}$. Control experiments were carried out with pyrene adsorbed onto silica particles. In this experiment without catalyst, no photochemical processes were observed. Degradation of physisorbed pyrene on solid substrates is usually explained in terms of reactive radical cation intermediate formation. These radicals can follow a variety of reaction pathways, including the introduction of hydroxyl and carbonyl groups into the ring system. ${ }^{11,18}$ Several compounds, such as 1,6-pyrene-dione and 1,8-pyrene-dione, have been suggested as initial pyrene photochemical products. ${ }^{18}$ These molecules are potential intermediate products for the reaction studied here and may give rise to the spectral pattern observed in Figure 6.

\section{Spectroelectrochemistry}

The electrochemical behavior of aqueous pyrene adsorbed over a gold electrode at the anodic potential range is shown in Figure 7. Raman spectral changes for pyrene are observed at potentials greater than $+0.6 \mathrm{~V}$. Vibrational modes at 1498 and $1376 \mathrm{~cm}^{-1}$ appear and are enhanced as the potential is made more positive.

Again, these changes are assigned to oxidation of the adsorbed molecule, as oxidation product modes were detected at 1774,1498 and $1376 \mathrm{~cm}^{-1}$. At $1.1 \mathrm{~V}$, the 


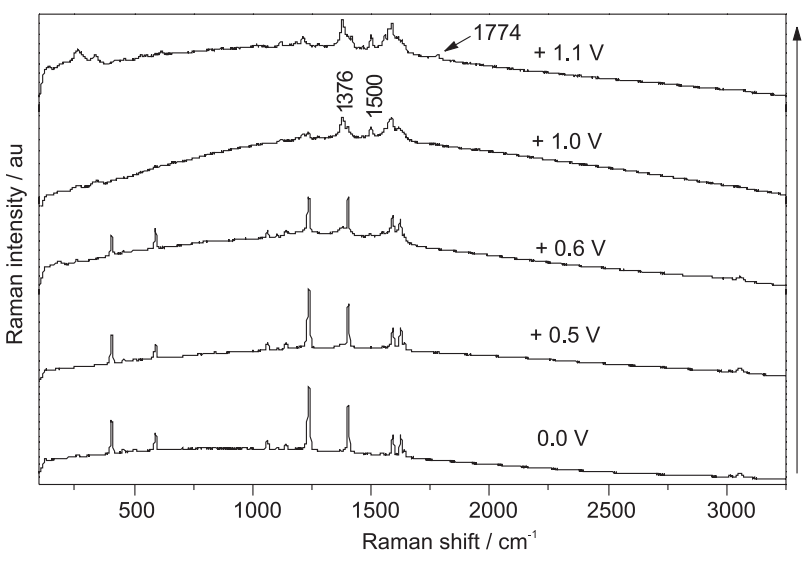

Figure 7. In situ Raman spectra of pyrene adsorbed on a gold surface in $\mathrm{KCl} 0.1$ mol.L-1 aqueous solution obtained at cathodic polarization. Potentials shown are versus $\mathrm{Ag} / \mathrm{AgCl}$ ); $\lambda_{\text {exc. }}=632.8 \mathrm{~nm}$. The arrow on the right indicates the order in which traces were taken.

characteristic vibrational modes of pyrene are no longer observed. The observed oxidation potential agrees with the work of Marzur and Banchard, ${ }^{11}$ where the voltammetric curves of aminopyrene covalently attached to gold were examined. Electrochemical data revealed that surface bonded aminopyrene undergoes oxidation at $c a .0 .96 \mathrm{~V}$, forming a cation radical. This highly reactive species was found to undergo rapid reactions in order to form more stable compounds.

Electrochemically oxidized compounds produced here have a carbonyl stretching frequency at $1774 \mathrm{~cm}^{-1}$, which is significantly higher than the carbonyl frequency characteristic of photochemical degradation products (ca. $1667 \mathrm{~cm}^{-1}$ ). This higher frequency mode can be assigned to an ester group carbonyl. Results presented here demonstrate that, for pyrene, oxidation products formed by photocatalysis at a semiconductor/air interface and via electrochemistry in aqueous solution are different. While photocatalysis results in a quinone functional group, electrochemical oxidation is found to produce an ester, possibly a cyclic one. This is summarized in Figure 8. In fact, the formation of a lactone was proposed by Wen et al. ${ }^{10}$ in the study of $\mathrm{TiO}_{2}$-mediated photodegradation of pyrene in aqueous solution.

Fluorene: photochemistry over $\mathrm{TiO}_{2}$

Photocatalytic processing of fluorene adsorbed on $\mathrm{TiO}_{2}$ was also investigated, as shown in Figure 9. Fluorene structural changes were observed after $60 \mathrm{~min}$ of UV irradiation, as indicated by appearance of a carbonyl vibrational mode at $1710 \mathrm{~cm}^{-1}$. This oxidative degradation reaction also leads to a decrease of aliphatic $\mathrm{C}-\mathrm{H}$ stretching modes, suggesting the formation of a group within the 5-membered fluorene ring structure. Formation of 9-fluorenone can explain this structural change, as this compound is commonly identified in environmental samples. ${ }^{19}$ The observed oxidized intermediate is found to degrade substantially. No organic products were detected on the $\mathrm{TiO}_{2}$ surface after $19 \mathrm{~h}$ of photolysis. In this case, photodegradation in the semiconducting/air interface resulted in the total mineralization of the PAH.

\section{General considerations}

Considering the similar products of anthracene and pyrene presented above, it is reasonable to suppose that major oxidation mechanisms could be analogous for both compounds during photocatalysis and electrochemistry.

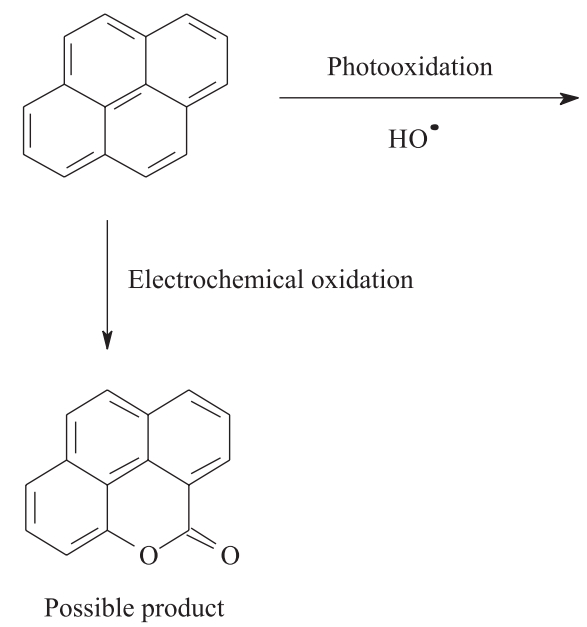<smiles>O=C1C=CC2C=CC3C(=O)C=Cc4ccc1c2c43</smiles>

1,8-pyrene-dione<smiles></smiles>

1,6-pyrene-dione

Figure 8. Oxygenated products suggested to photo and electrochemical oxidation of pyrene. The diones were observed in the photooxidation over $\mathrm{TiO}_{2}$ and the lactone is a product proposed from a $1774 \mathrm{~cm}^{-1}$ band observed after the electrochemical oxidation of the PAH, characteristic of esters. ${ }^{10}$ 


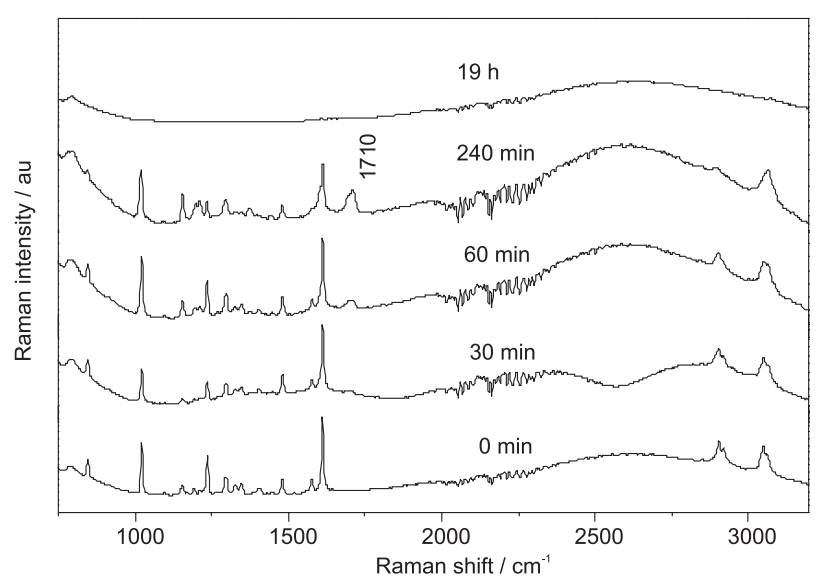

Figure 9. FT-Raman spectra for fluorene adsorbed on a $\mathrm{TiO}_{2}$ surface (2 $\mathrm{wt} \%)$ corresponding to progressively longer UV-irradiation times (bottom to top); $\lambda_{\text {exc. }}=1064 \mathrm{~nm}$.

However, our results reveal the formation of different pyrene oxidation products for electrochemical and photocatalytic processing.

This issue can be addressed in a reasonably simple way, thinking in aromatic chemistry. Anthracene (and so phenanthrene, for example) possesses some non-aromatic (or less aromatic) carbon atoms (9 and 10) and this confers a certain reactivity to these atoms driving the oxidation (addition) reactions to these centers. So, we expect, that we will have the same product (9,10-anthraquinone) in every anthracene oxidation we perform. This would also be the case for fluorene and phenanthrene.

Pyrene, on the other hand, presents typically aromatic chemistry, governed to the regularities of nucleophilic and electrophilic substitutions. Thus, we expect indeed a much more complex chemistry and this is really observed in the experiments, through intriguing results.

We therefore suggest that, for PAHs, the major oxidizing agent initiating degradation reactions is distinct for photocatalytical and electrochemical processes. The first step in electrochemical oxidation reactions may be the formation of pyrene cation radicals. Photocatalytic degradation, on the other hand, could proceed via a different pathway, initiated in this case by hydroxyl radicals.

\section{Conclusions}

Spectroscopic techniques were used to study the electrochemical behavior of PAHs in aqueous solution and the heterogeneous reaction of solid $\mathrm{PAHs}$ on $\mathrm{TiO}_{2}$ upon UV irradiation. Time-resolved analysis of UV photo-induced PAH degradation, as well as the production of intermediates, was performed with FT-Raman spectroscopy. Raman spectral changes were observed during the photooxidation of PAHs adsorbed on $\mathrm{TiO}_{2}$, indicating the formation of oxidized intermediates with carbonyl functionality. The intermediate products formed during PAH electrochemical reactions were also spectroscopically monitored. We show that photodegradation of anthracene over $\mathrm{TiO}_{2}$ generates the same product as direct oxidation of the PAH adsorbed onto a gold electrode (i.e., 9,10 anthraquinone). In opposition to the behavior of anthracene, pyrene is found to form different oxidation products with photocatalytic and electrochemical processing. Photolysis induces the formation of a pyrenedione, while electrolysis forms an ester. A reasonable explanation of this difference in results is that photochemical and electrochemical oxidation reactions proceed via different mechanisms. While photocatalytic degradation of PAHs over $\mathrm{TiO}_{2}$ is initiated with hydroxyl radicals, electrochemical oxidation is initiated with direct electron transfer from adsorbed PAH to the electrode, generating PAH cation radicals that undergo subsequent reactions.

This systematic study of chemical reactions resulting in the heterogeneous catalysis of PAHs is relevant to the understanding of complex chemical transformations that can occur in atmospherically suspended particulate matter. Knowledge of PAH behavior during oxidation processes may also shed light on fundamental aspects of PAH reactivity, increasing the understanding of the formation of oxygenated PAH derivatives as potential secondary pollutants in aerosol reactions.

\section{Acknowledgements}

This work was supported by FAPESP and CNPq. Fellowships from CAPES and CNPq are gratefully acknowledged. The authors sincerely acknowledge significant contributions from Fernando L. Cassio, Profs Marcia L. A. Temperini and Renato S. Freire.

\section{References}

1. Manahan, S. E.; Environmental Chemistry, 8th ed., CRC Press: United States, 2005.

2. Pereira Netto, A. D.; Moreira, J. C.; Dias, A. E. X. O.; Arbilla, G.; Ferreira, L. F. V.; Oliveira, A. S.; Barek, J.; Quim. Nova 2000, 23, 765.

3. Chiang, H. P.; Mou, B.; Li, K. P.; Chiang, P.; Wang, D.; Lin, S. J.; Tse, W. S.; J. Raman Spectrosc. 2001, 32, 45.

4. Lopes, W. A.; Pereira, P. A. P.; Viertler, H.; Andrade, J. B.; J. Braz. Chem. Soc. 2005, 16, 1099.

5. Konstantinou, I. K.; Albanis, T. A.; Appl. Catal., B 2003, 42, 319.

6. Konstantinou, I. K.; Albanis, T. A.; Appl. Catal., B 2004, 49, 1.

7. Pal, B.; Sharon, M.; J. Mol. Catal. A: Chem. 2000, 160, 453. 
8. Sabate, J.; Bayona, J. M.; Solanas, A. M.; Chemosphere 2001, $44,119$.

9. Wen, S.; Zhao, J.; Sheng, G.; Fu, J.; Peng, P.; Chemosphere 2002, 46, 871 .

10. Wen, S.; Zhao, J.; Sheng, G.; Fu, J.; Peng, P.; Chemosphere 2003, 50, 111.

11. Mazur, M.; Blanchard, G. J.; J. Phys. Chem. B 2004, 108, 1038.

12. Lee, C. J.; Kang, J. S.; Park, Y.; Rezaul, K. M.; Lee, M. S.; Bull. Korean Chem. Soc. 2004, 25, 1779.

13. Corio, P.; Rubim, J. C.; J. Phys. Chem. 1995, 99, 13217.

4. Sant'Ana, A. C.; Corio, P.; Temperini, M. L. A.; Quim. Nova 2006, 29, 805.

15. Corio, P.; Rubim, J. C.; Aroca, R.; Langmuir 1998, 14, 4162.
16. Costa, J. C. S.; Sant'Ana, A. C.; Corio, P.; Temperini, M. L. A.; Talanta 2006, 70, 1011.

17. Olson, L. G.; Uibel, R. H.; Harris, J. M.; Appl. Spectrosc. 2004, 58, 1394.

18. Reyes, C. A.; Medina, M.; Crespo-Hernandez, C.; Cedeno, M. Z.; Arce, R.; Rosario, O.; Steffenson, D. M.; Ivanov, I. N.; Sigman, M. E.; Dabestani, R.; Environ. Sci. Technol. 2000, 34, 415.

19. Casellas, M.; Fernandez, P.; Bayona, J. M.; Solanast, A. M.; Chemosphere 1995, 30, 725.

Received: March 26, 2008

Web Release Date: November 14, 2008

FAPESP helped in meeting the publication costs of this article. 